\title{
Diving behaviour of albatrosses: implications for foraging ecology and bycatch susceptibility
}

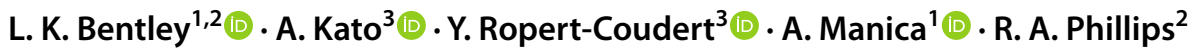

Received: 19 June 2020 / Accepted: 29 January 2021 / Published online: 17 February 2021

(c) The Author(s) 2021

\begin{abstract}
Diving is an ecologically important behaviour that provides air-breathing predators with opportunities to capture prey, but that also increases their exposure to incidental mortality (bycatch) in commercial fisheries. In this study, we characterised the diving behaviour of 26 individuals of three species, the black-browed albatross Thalassarche melanophris, grey-headed albatross T. chrysostoma and light-mantled albatross Phoebetria palpebrata, breeding at Bird Island, South Georgia. Individuals were tracked using Global Location Sensor (GLS)-immersion loggers and time-depth recorders (TDRs) and, for two species, Global Positioning System (GPS) loggers. Although the TDRs recorded 589 dives (defined in this paper as submersion $>1 \mathrm{~m}$ ), average dive depths and durations were just 1.30-1.49 $\mathrm{m}$ and 2.5-3.3 s, respectively, for the three species. In addition, many individuals (22\% of black-browed, $20 \%$ of grey-headed, and $57 \%$ of light-mantled albatrosses; total $n=9,10$ and 7 individuals, respectively) did not dive at all. Most dives occurred at the distal end of foraging trips and were rare during the commuting phase. No dives took place in darkness, despite long periods spent on water at night. The limited and shallow dive activity contrasts with impressions from a previous study using capillary-tube depth gauges (which are less accurate than TDRs) and has implications for the susceptibility of albatrosses to bycatch on longlines. This study provides further support for regulations requiring night setting and increased sink rates of baited hooks to help mitigate albatross bycatch.
\end{abstract}

\section{Introduction}

Many seabirds, including penguins, cormorants, alcids, diving petrels and some shearwaters are considered specialist divers, often foraging at depths $>10 \mathrm{~m}$, whereas most other seabird species undertake only brief, shallow dives or feed largely at the surface (Croxall and Prince 1980; Harper 1987; Navarro et al. 2014). As various types of fishing gear (e.g. gillnets, trawls, pelagic and demersal longlines) are set and operate at different depths, diving capability is a key determinant of the likelihood of incidental mortality (bycatch) (Anderson et al. 2011; Žydelis et al. 2013;

Responsible editor V. H. Paiva.

L. K. Bentley

1kb45@cam.ac.uk

1 Department of Zoology, University of Cambridge, Cambridge, UK

2 British Antarctic Survey, Natural Environment Research Council, High Cross, Cambridge, UK

3 Centre D’Etudes Biologiques de Chizé, La Rochelle Université, Villiers en Bois, France
Crawford et al. 2017). Many seabird species are of high conservation concern because of negative interactions with fisheries (Phillips et al. 2016). As such, quantifying their diving behaviour is fundamental to understanding not just their ability to access prey, but also their susceptibility to this anthropogenic threat.

Bycatch in commercial fisheries is a main cause of population declines in many albatrosses and large petrels (Phillips et al. 2016). These species mature slowly, have high adult survival, and low reproductive output, which means any additional adult mortality-e.g., as bycatch—can have major implications for demography (Thomson et al. 2015; Pardo et al. 2017). Research on bycatch mitigation in commercial fisheries has been extensive in recent years (Sullivan et al. 2018; Robertson et al. 2018; Jiménez et al. 2018). In longline fisheries, use of bird-scaring lines (BSLs; also called streamer or tori lines) aims to discourage birds from targeting hooks during setting, and heavier line-weighting regimes aim to sink baits more rapidly beyond their reach (Jiménez et al. 2018). Baits may also be released below the surface by a machine (Robertson et al. 2018), or devices (such as Hookpods) used to cover the sharp section of the hook until it reaches a particular depth (Sullivan et al. 2018; 
Goad et al. 2019). As pelagic and demersal longliners in the Southern Hemisphere set $100 \mathrm{~s}$ of millions of hooks per year (Clay et al. 2019), it is critical to know at what depths these pose a threat to different seabirds to refine bycatch mitigation strategies, including minimum line-weighting regimes and aerial extents of BSLs. Information on diurnal activity patterns, including diving, of seabirds can also inform policies on restricting setting times.

In general, albatrosses appear morphologically to be poorly adapted to diving. Indeed while the typical relationship for most orders of seabirds is that maximum dive depth scales positively with body mass, this does not apply in the Diomedeidae (Navarro et al. 2014). Early studies of albatrosses deployed capillary-tube depth gauges to measure the absolute maximum dive depth during the deployment period (Prince et al. 1994), whereas more recently, time-depth recorders (TDRs) have been used to record depth, duration and shape of all dives (Hedd et al. 1997; Huin and Prince 1997). Dive depths recorded by capillary depth gauges were unexpectedly high, ranging from mean $\pm \mathrm{SD}$ and absolute maxima of $2.5 \mathrm{~m} \pm 1.3 \mathrm{~m}$ and $4.5 \mathrm{~m}$ in black-browed albatrosses Thalassarche melanophris, to $4.7 \mathrm{~m} \pm 3.4 \mathrm{~m}$ and $12.4 \mathrm{~m}$, respectively, in light-mantled albatrosses Phoebetria palpebrata, which led the authors to speculate that the latter species was as proficient at diving as gannets (Sulidae) (Prince et al. 1994). Subsequent studies using TDRs have recorded shallower diving in other albatrosses, with mean and maximum dive depths of $0.6 \mathrm{~m} \pm 0.2 \mathrm{~m}$, and $2.5 \mathrm{~m}$, respectively, in black-footed albatrosses Phoebastria nigripes, and of $1.9 \mathrm{~m} \pm 1.7 \mathrm{~m}$ and $7.4 \mathrm{~m}$ in shy albatrosses T. cauta (Hedd et al. 1997; Kazama et al. 2019). A study of three black-browed albatrosses using a back-mounted camera with a pressure sensor also found that dives were infrequent and shallow (mean depth $1.46 \mathrm{~m}$ ) (Sakamoto et al. 2009). Several studies have shown that capillary gauges overestimate depth, possibly because of high pressures experienced when birds hit the water at speed (Burger and Wilson 1988; Hedd et al. 1997; Navarro et al. 2014). Nor do they record dive frequency or duration, better indications of foraging style and breath-hold capability. As capillary gauges only record the single deepest dive during each deployment, this inflates the importance of these outliers when drawing ecological inferences. Therefore, TDRs allow more meaningful ecological conclusions to be drawn.

A detailed understanding of albatross behaviour at sea requires a combination of bio-logging devices. Global Positioning System (GPS) loggers, geolocators (Global Location Sensor or GLS loggers) and satellite transmitters allow habitat use to be determined, and saltwater immersion loggers allow flights and landings to be distinguished. Opportunistic foraging can be inferred by landings in the middle of directional transits, and area restricted search by higher turning rates and increased landings as the predator exploits a profitable patch of resources (Catry et al. 2004; Weimerskirch et al. 2007). Feeding attempts cannot be distinguished from resting using immersion data, which is an important limitation given albatrosses spend long periods on the water overnight (Weimerskirch and Guionnet 2002; Catry et al. 2004; Phillips et al. 2005; Phalan et al. 2007). Albatrosses were initially thought to be primarily nocturnal foragers, as grey-headed T. chrysostoma and light-mantled albatrosses, in particular, feed their chicks with substantial amounts of vertically-migrating squid, and all species were observed feeding at sea at night (Harper 1987; Prince and Morgan 1987). More recent studies propose that while some sitand-wait feeding occurs at night, this strategy is only used because visual detection of prey is difficult in low light conditions (Phalan et al. 2007; Weimerskirch et al. 2007). Further evidence supporting largely diurnal foraging is that the eyes of albatrosses are adapted for the visual pursuit of prey in daylight (Martin 1998). Timing of activity has important implications for conservation, as albatross bycatch is reduced when longlines are set at night (Bull 2007; Jiménez et al. 2020). Although immersion events can be interpreted in different ways, dive events are almost certainly indicative of feeding attempts, and their presence or absence can clarify foraging style.

The main objectives of this study were to quantify and contextualise dive events using both immersion and location data, and to construct a more comprehensive picture of albatross foraging behaviour in the breeding season. We aimed to accurately characterise diving depth, duration and frequency in three albatross species, including black-browed albatrosses and grey-headed albatrosses (both frequently caught in longline fisheries) and light-mantled albatrosses (previously suggested to be the most proficient divers; Prince et al. 1994). We hypothesised that typical dive depths for these species would be much shallower than the maximum depths previously reported using capillary gauges. As the eyes of albatrosses are adapted for diurnal foraging (Martin 1998), and they are generally more active in daylight than darkness (Phillips et al. 2007), we predicted that most dive activity would occur during the day. Results are discussed in the context of susceptibility to bycatch in longline fisheries, and the implications for refining approaches to bycatch mitigation.

\section{Materials and methods}

\section{Device deployments}

All devices were deployed at Bird Island, South Georgia $\left(54^{\circ} 00^{\prime} \mathrm{S}, 38^{\circ} 03^{\prime} \mathrm{W}\right)$ on breeding birds during the austral summer 2009/10. Black-browed albatrosses $(n=9)$ and grey-headed albatrosses $(n=10)$ were tracked during 
brood-guard, and light-mantled albatrosses $(n=7)$ during incubation, in all cases for a single foraging trip. Three types of GPS logger were used: i-gotU GT-120 (MobileAction Technology, Taiwan; $25 \mathrm{~g}$ ), MiniGPSlog (earth \& OceanTechnology, Germany; $25 \mathrm{~g}$ ) or MicroGPSlog (earth $\&$ OceanTechnology, Germany; $10 \mathrm{~g}$ ). These were usually set to obtain a fix every 10 or $15 \mathrm{~min}$ and attached to mantle feathers using fabric $\left(\right.$ Tesa $\left.^{\circledR}\right)$ tape. In addition, a combined GLS-immersion logger (Mk19, British Antarctic Survey, Cambridge, UK; $2.5 \mathrm{~g}$ ) attached by a cable-tie to a plastic ring was deployed on one tarsus, and a TDR (Cefas G5, Cefas Technology Ltd, Lowestoft, UK; $2.7 \mathrm{~g}$ or $6.5 \mathrm{~g}$ ), also on a plastic ring, on the other tarsus. (Details of devices used for each individual available in the electronic supplementary material.) Attachment of devices took $<10$ min. Maximum instrument loads were $<1.5 \%$ of mean body mass, and hence well below the threshold of 3\% above which deleterious effects are more common in albatrosses (Phillips et al. 2003). TDRs had a $0.03 \mathrm{~m}$ depth resolution, and on black-browed and grey-headed albatrosses recorded depth every $1 \mathrm{~s}$ for the duration of the foraging trip. Those on light-mantled albatrosses recorded depth every $1 \mathrm{~s}$ on every third day. GLSimmersion loggers tested for saltwater immersion every $3 \mathrm{~s}$ and recorded every change of state from wet to dry and vice versa that lasted $6 \mathrm{~s}$ or more, providing the timing of landings and take-offs from the water. The calculated immersion times included all time that the bird had its legs in the water (i.e. resting, surface feeding, and diving). The term "diving" hereafter refers only to events during which the tarsus of the bird submerges to $>1 \mathrm{~m}$ depth.

\section{Dive analysis}

Depth data were manually corrected for a drifting surface level. The dive threshold was set at $1 \mathrm{~m}$ depth (Navarro et al. 2014; Bennison et al. 2018), as this best reflects the accuracy of the pressure sensor (1\% at 10 bar device range). This threshold also reduces noise associated with surface pressure changes and wave action and ensures recorded 'dives' reflect prey capture attempts rather than other surface behaviours. We acknowledge that because the TDR was mounted on the tarsus, a dive record of $1 \mathrm{~m}$ may represent a bird whose head can access prey beyond this depth, given a body length of $\sim 0.8 \mathrm{~m}$. Dive parameters (maximum depth, duration) were extracted for each dive. Uncertainty, particularly at shallow depths, is hard to quantify without accurate data on in-situ barometric pressure, but by using a $1 \mathrm{~m}$ threshold we were able to more confidently remove false dive events from analysis if they did not meet minimum criteria as follows: (i) start depth $\geq 0 \mathrm{~m}$, (ii) depth change rate at the start of the dive $<1 \mathrm{~m} / \mathrm{s}$, (iii) depth change rate at the end of the dive $<2 \mathrm{~m} / \mathrm{s}$, and (iv) depth change rate just before the start of the dive $\leq 0 \mathrm{~m} / \mathrm{s}$, confirmed by visual inspection of all dives. Dives were analysed using IGOR pro (Wavemetrics, version 6.3, Portland, OR, USA). Mean depth, duration and frequency of dives were calculated for each individual. A Fisher's exact test was used to compare the proportions of non-divers between species. Dives were also assigned to daylight (between sunset and sunrise), twilight (from civil twilight to the nearest sunset or sunrise), and darkness (between civil twilights) based on GPS location and time, using standard astronomical calculations in the $\mathrm{R}$ package SGAT (Sumner et al. 2009).

\section{GPS and immersion analysis}

GPS tracks were interpolated to 1-s intervals for behavioural matching and 5-min intervals for visualisation using the $\mathrm{R}$ package adehabitatLT (Calenge 2006), and the start and end of each foraging trip was estimated to \pm 5 min from GPS locations, confirmed by immersion data (first wet event, as albatrosses almost always bathe before departing on a trip; Granadeiro et al. 2018). Immersion and dive events were then matched by time to GPS locations interpolated at 1-s intervals for black-browed and grey-headed albatrosses. GPS data were unavailable for light-mantled albatrosses because of battery depletion or water ingress into the devices. Total immersion time was calculated for each trip. Immersion events were categorised as occurring in daylight, twilight or darkness in the same manner as dive events (described above). Sample sizes varied between analyses in cases where, for the same bird, one type of data was unavailable (e.g. GPS). All processing of GPS tracks, summarising and cleaning of data, descriptive statistics and mapping were undertaken in $\mathrm{R}$ version 3.6.2 (R Core Team 2019). Values are given as the mean \pm SD unless indicated otherwise.

\section{Results}

Average dive depths, durations and frequencies (per day and per trip) for grey-headed and black-browed albatrosses tracked during brood-guard, and light-mantled albatrosses tracked during incubation from Bird Island (South Georgia) are shown in Table 1. No dives were recorded for two of the nine black-browed, two of the 10 grey-headed, and four of the seven light-mantled albatrosses that were tracked. There was no statistically significant difference between these ratios (two-tailed Fisher's exact test, $P=0.28$ ). The mean maximum depths of diving individuals from all three species were $<1.5 \mathrm{~m}$, and the deepest dive for any bird was $6.0,3.4$ and $2.0 \mathrm{~m}$ for black-browed, grey-headed and light-mantled albatrosses, respectively. Mean dive durations ranged from 2.5-3.3 s. Number of dives per trip and maximum dive depths were highly variable between individuals (Fig. 1). 
Table 1 Summary of dive events for three albatross species tracked from Bird Island (South Georgia), in austral summer 2009/10. 'Non-divers' indicates birds for which no dive events were recorded by the TDRs. All values are means \pm SD unless otherwise stated

\begin{tabular}{|c|c|c|c|c|c|c|c|c|}
\hline Species & Breeding stage & $\begin{array}{l}\text { Dive depth }(\mathrm{m}) \text {; } \\
\text { max observed } \\
\text { depth }\end{array}$ & $\begin{array}{l}\text { Dive duration } \\
\text { (s); } \\
\text { max duration }\end{array}$ & Dives per trip & Dives per day & $n$ dives & $n$ birds tracked & $n(\%)$ non-divers \\
\hline $\begin{array}{l}\text { Black-browed } \\
\text { albatross }\end{array}$ & Brood-guard & $1.49 \pm 0.17 ; 6.0$ & $3.30 \pm 0.6 ; 15$ & $36.55 \pm 53.79$ & $17.83 \pm 27.15$ & 329 & 9 & $2(22 \%)$ \\
\hline $\begin{array}{l}\text { Grey-headed } \\
\text { albatross }\end{array}$ & Brood-guard & $1.47 \pm 0.34 ; 3.4$ & $2.85 \pm 0.9 ; 8$ & $22.50 \pm 44.74$ & $9.13 \pm 16.62$ & 225 & 10 & $2(20 \%)$ \\
\hline $\begin{array}{l}\text { Light-mantled } \\
\text { albatross }\end{array}$ & Incubation & $1.30 \pm 0.32 ; 2.0$ & $2.50 \pm 0.9 ; 5$ & NA & $0.44 \pm 0.23$ & 10 & 7 & $4(57 \%)$ \\
\hline
\end{tabular}

Fig. 1 Dive depths recorded from black-browed albatross (BBA) grey-headed albatross (GHA) and light-mantled albatross (LMA) tracked from Bird Island (South Georgia) during the 2009/10 breeding season. BBA and GHA tracked during brood-guard, and LMA tracked during incubation. Jitter is used to emphasise variation in a number of points (dives) between individuals. Note that for all species only the IDs of birds that dived appear on the plot
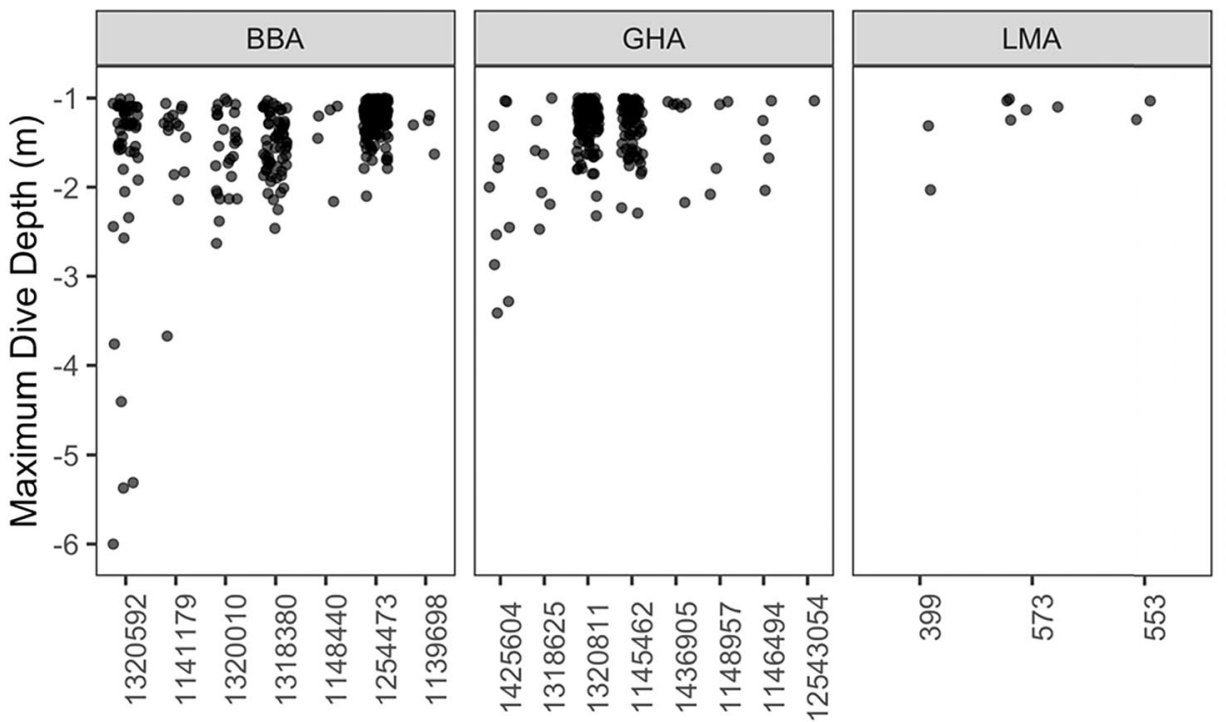

Bird ID
Grey-headed albatrosses generally dived at the most distal portions of foraging tracks, and travelled north of Bird Island to the Antarctic Polar Front, whereas with one exception, foraging and dives in black-browed albatrosses took place closer to South Georgia (Fig. 2).

Average proportion of time spent immersed was $25.5 \pm 14.5 \%$ of brood-guard trips lasting $1.9 \pm 0.7$ days in black-browed albatrosses $(n=9)$ and $20.4 \pm 2.6 \%$ of trips lasting $2.8 \pm 0.4$ days in grey-headed albatrosses $(n=8)$; in all cases, total time spent diving was $<0.5 \%$ of the trip (Fig. 3a). Light-mantled albatrosses $(n=7)$ spent an average of $27.2 \pm 7.8 \%$ of incubation trips of $14.2 \pm 5.0$ days immersed; total time spent diving was always $<10 \mathrm{~s}$ (Fig. 3b).

Of the total time that black-browed albatrosses $(n=8)$ spent on water, $42.7 \pm 16.9 \%$ occurred during the day, $4.1 \pm 3.4 \%$ during twilight, and $53.2 \pm 18.3 \%$ at night. In grey-headed albatrosses $(n=8), 25.2 \pm 8.3 \%$ of immersion occurred during the day, $2.8 \pm 3.2 \%$ during twilight, and $72.0 \pm 10.5 \%$ at night. (Fig. 4).
More than $95 \%$ of dives that could be matched to GPS locations ( $n=308$, black-browed albatrosses; $n=219$, greyheaded albatrosses) occurred during daylight, with all others (3.6\% and $4.1 \%$ of dives for black-browed albatrosses and grey-headed albatrosses, respectively) occurring during twilight. No dives were recorded in darkness.

\section{Discussion}

Here we integrate measures of albatross activity at sea, combining geographic location, flights, landings, and diving behaviour during the brood guard (black-browed, grey-headed) and incubation (light-mantled) stages of the breeding season. We provide detailed data on diving depths, durations, frequencies and timing for albatrosses using TDRs, and show that dives are infrequent, diurnal and shallow in all species. Indeed, albatrosses show greatly reduced diving activity than might be inferred from the maximum dive depths estimated using capillary depth gauges for these 


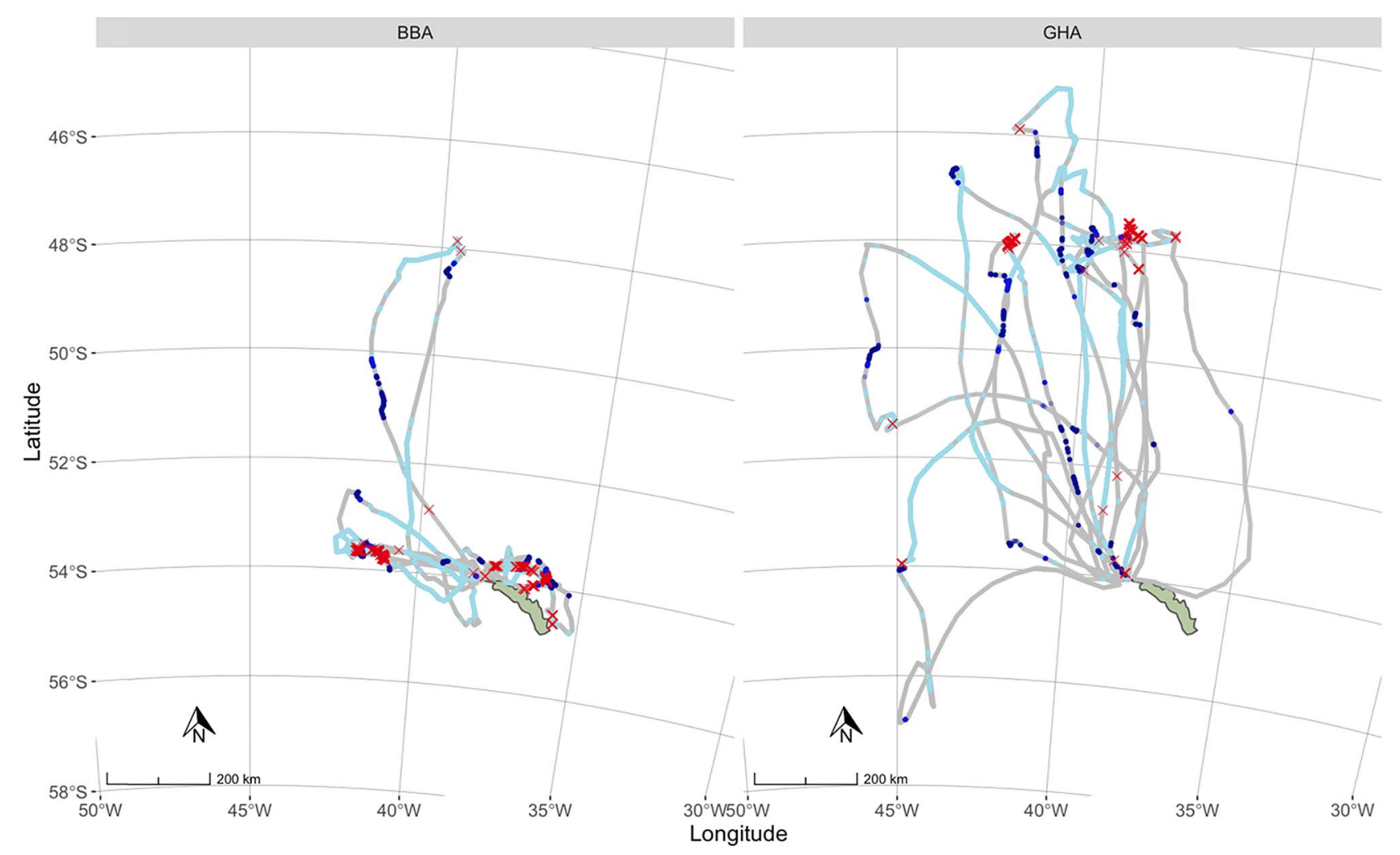

Fig. 2 GPS tracks (grey), immersion events during the day (light blue points), twilight (medium blue points) and night (dark blue points) and dive events (red X) for black-browed albatrosses (left, $n=8$ ), and grey-headed albatrosses (right, $n=8$ ) tracked from Bird Island, South

species at the same study site close to 30 years ago (Prince et al. 1994).

Defining what constitutes a dive is critically important when comparing dive metrics among species. Reaching prey located at $0.5-0.7 \mathrm{~m}$ depths may only require a surface dive for a large bird, whereas in smaller species where this distance is at least one-maybe two-times their body length, it will represent a wing-propelled pursuit dive (Harper 1987). Previous work on grey-headed albatrosses using TDRs considered a dive to be any record deeper than $0.1 \mathrm{~m}$ (Huin and Prince 1997), whereas we only considered dives to occur when the tarsus exceeded a threshold of $1 \mathrm{~m}$ (a common threshold used in more in recent work using the same logger type (albeit for deeper diving species), e.g. Navarro et al. (2014), Bennison et al. (2018)). This not only better accounts for levels of sensor accuracy and data noise, but we consider it to be more ecologically appropriate as the average body length of these birds is $0.8 \mathrm{~m}$ (Warham 1996). For a bird of this size to record a tarsus depth $>1 \mathrm{~m}$, we can be more confident that we have measured a meaningfully different behaviour than surface foraging. Moreover, all immersions (whether or not they involve diving), can be recorded more
Georgia (light green), during brood-guard in austral summer 2009/10. NB: Continuous daylight immersion events covering large distances do not represent fast on-water drifting, but rather repeated switching between flight and landings, i.e. likely foraging (colour figure online)

efficiently and consistently using immersion sensors rather than relying on shallow depth values recorded by a TDR.

The distinction between all landings and just dives is important when drawing conclusions about physiology and ecology. For example, Huin and Prince (1997) suggested that in grey-headed albatrosses, the percentage of energy gained by diving might be as high as $45 \%$, whereas this seems unrealistic using a dive threshold of $1 \mathrm{~m}$ as in our study, because three $(30 \%)$ of the ten birds of this species that we tracked dived $<5$ times, and two (20\%) did not dive at all. The most common strategy for prey acquisition was, therefore, likely to be feeding within 1 or $2 \mathrm{~m}$ of the surface, with occasional dives (or "plunges", as in Harper 1987) both while in transit and while undertaking area-restricted search, and rare bouts of numerous successive surface dives, seen only in a few individuals (e.g. see GHA 1320811, GHA 1145462 in Fig. 1). Further work combining tracking with both TDRs and stomach temperature probes is required to make any claims about energy gain with certainty. Had these bouts of successive dives occurred in areas with known fishing activity, it may have indicated vessel interactions; however, this was not the case given there is a seasonal closure of fisheries 
a

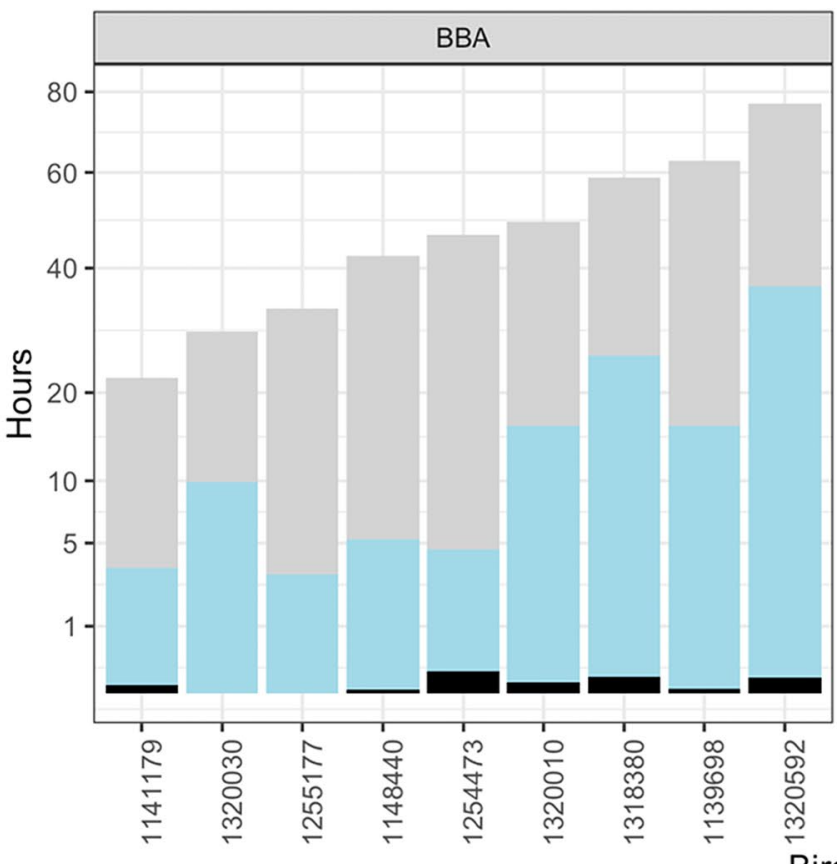

Bird ID

b

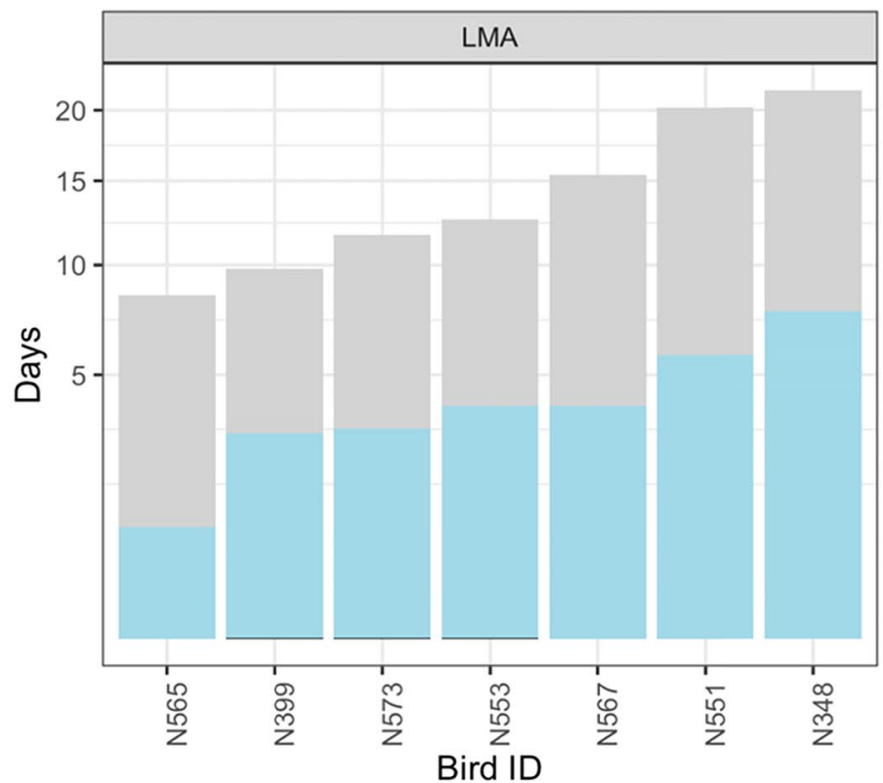

Fig. 3 Time spent diving (black), immersed (light blue) and flying (grey) for: a individual black-browed (left panel) and grey-headed (right panel) albatrosses tracked during brood-guard; and b) for individual light-mantled albatrosses tracked during incubation from Bird

in the waters around South Georgia and no evidence for illegal fishing in recent years (Tancell et al. 2016). For further analyses of foraging habitat selection in these grey-headed albatrosses, see Scales et al. (2016).

Our study affirms the large amounts of time spent feeding at depths $<2 \mathrm{~m}$ for these species, because diving was very infrequent and shallow, and a high proportion of foraging

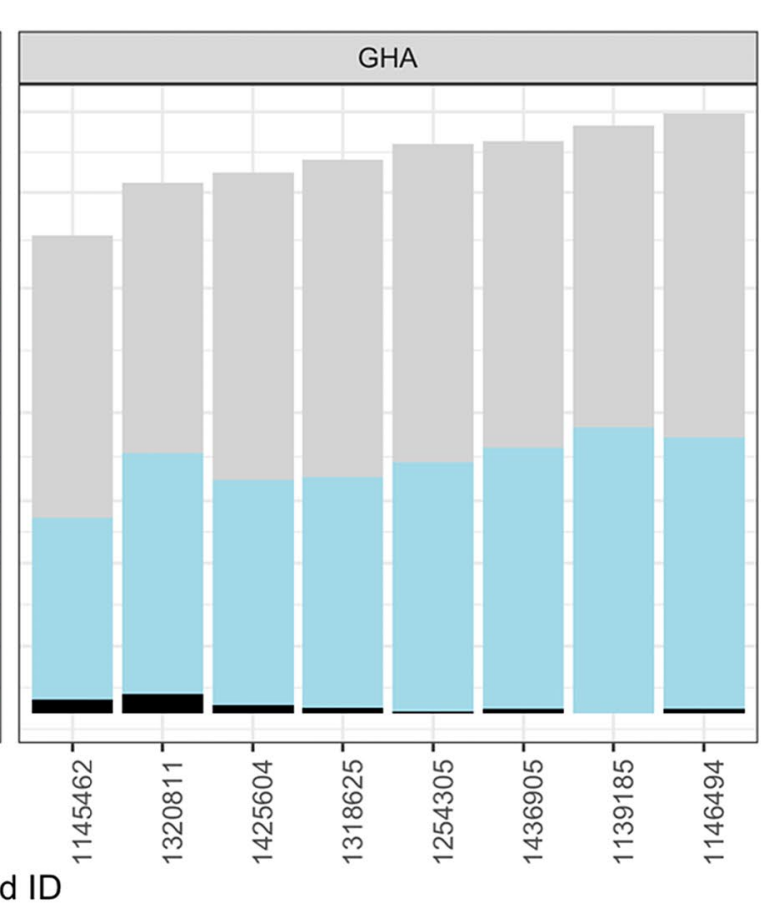

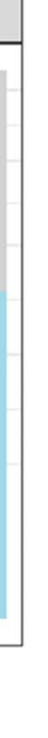

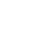

Island (South Georgia), in austral summer 2009/10. Note the square root scale on the $Y$ axis and variation in $Y$ axis scale between panels a and $\mathrm{b}$ (colour figure online)

trips was spent on the water's surface. The absence of diving overnight reinforces previous work noting the importance of daylight foraging, despite the long periods of time on the water at night (Catry et al. 2004; Phalan et al. 2007). The proportion of time spent on the water was broadly similar within and between species, although as in previous studies of at-sea activity patterns (Phalan et al. 2007; Mackley 


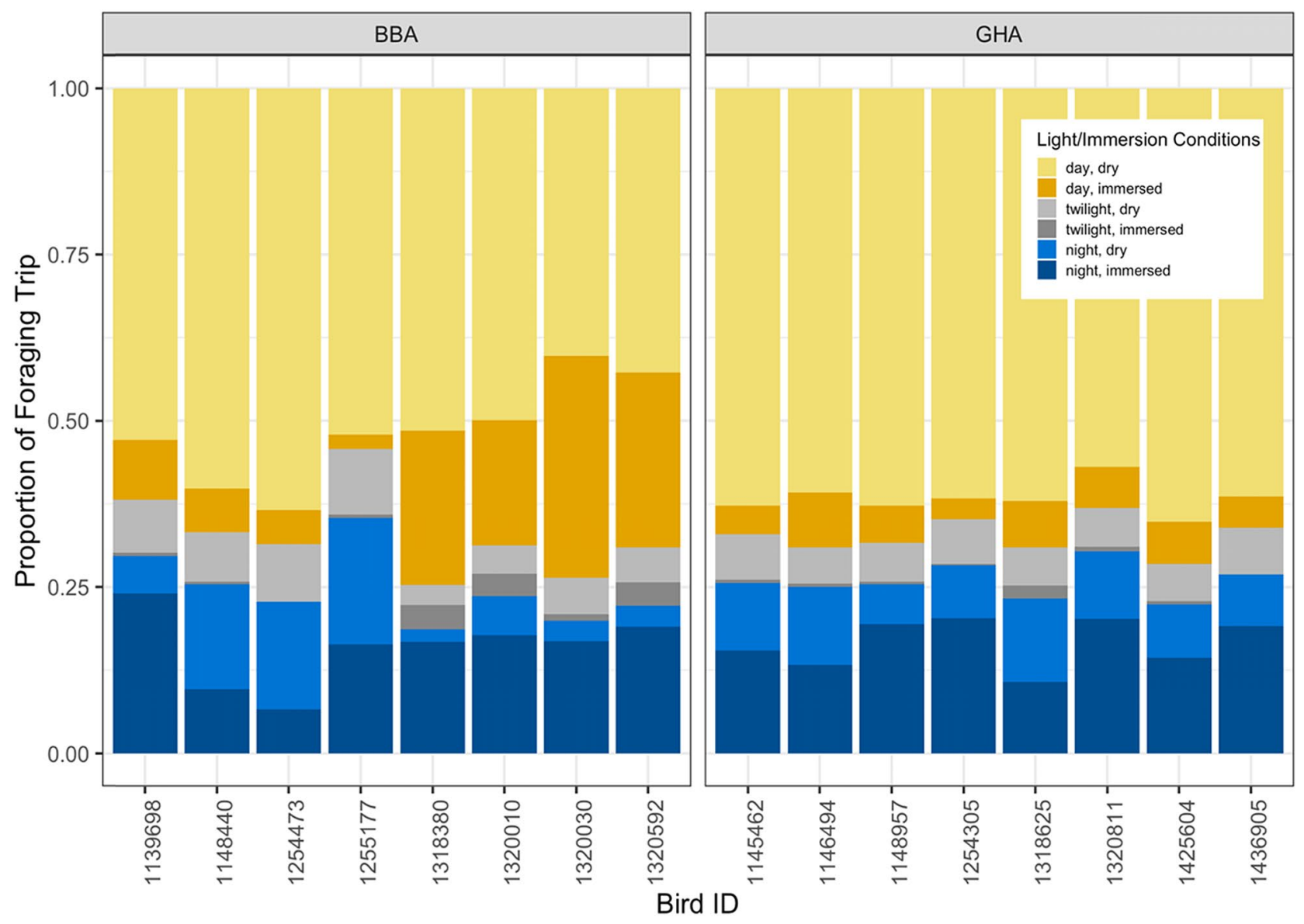

Fig. 4 Total proportions of foraging trip spent immersed (dark shades) and dry (light shades) during daylight (yellow), twilight (grey) and darkness (blue), for individual black-browed (BBA) and

et al. 2011), there were very large differences in behaviour between individuals (Fig. 2). The high variability in landing and diving rates suggest possible individual specialisation, and perhaps that diving is undertaken only by birds with particular skills or preferences. Alternatively, the few individuals that dived numerous $(>100)$ times on a single trip may have simply encountered a highly productive patch of prey for which this technique allowed efficient exploitation or that was driven upwards by subsurface predators. Further tracking of multiple foraging trips by individuals over an extended period might indicate if this large variation in dive behaviour is due predominantly to extrinsic (e.g. prey availability) or intrinsic (e.g. energy needs) factors.

Energy requirements during brood-guard are higher than during incubation: parents must meet both their own and their chick's energy requirements while foraging, are constrained to shorter and closer foraging trips, and wandering albatrosses Diomedea exulans are known to lose mass during this period (Weimerskirch and Lys 2000). Nonetheless, there was no statistically significant difference in dive rates grey-headed (GHA) albatrosses tracked during brood-guard from Bird Island (South Georgia), in austral summer 2009/10 (colour figure online)

between species, even though the light-mantled albatross in incubation appeared to dive less frequently than blackbrowed or grey-headed albatross in brood-guard. Based on immersion data, foraging bout lengths and frequencies are broadly similar between incubation and brood-guard (Weimerskirch and Guionnet 2002; Phalan et al. 2007), and hence dive frequency and characteristics may also be comparable across breeding stages. Any potential effects of the breeding stage on diving behaviour would need to be confirmed by further tracking.

Our results confirm that all three genera of small albatrosses (Phoebetria and Thalassarche, this study; Phoebastria, (Kazama et al. 2019)) are infrequent, short and shallow divers compared with most other seabirds, reaching $<1.5 \mathrm{~m}$ on average. In contrast, many shearwaters are far more proficient, attaining mean maximum depths of $17.8 \mathrm{~m}$ Puffinus yelkouan, $9.6 \mathrm{~m} \mathrm{P}$. puffinus, and $15.9 \mathrm{~m}$ Ardenna grisea (Shaffer et al. 2009; Péron et al. 2013; Shoji et al. 2016), whereas the Calonectris shearwaters only dive to mean depths of 1-2 m (Paiva et al. 2010; Matsumoto 
et al. 2012; Grémillet et al. 2014). The Procellaria petrels are also proficient divers; grey petrels Procellaria cinerea and white-chinned petrels Procellaria aequinoctialis reach mean and absolute maximum diving depths, respectively, of $3.2 \pm 2.2 \mathrm{~m}$ and $22 \mathrm{~m}$, and $2.9 \pm 2.4 \mathrm{~m}$, and $17 \mathrm{~m}$ (Rollinson et al. 2014, 2016).

Although they are mostly shallow divers, albatrosses are clearly at high risk of bycatch behind longline vessels (Jiménez et al. 2014; Phillips et al. 2016). In accordance with our results indicating fewer landings and no diving in darkness, night setting of longlines is known to significantly reduce bycatch rates (Jiménez et al. 2020). In terms of compliancemonitoring, night setting has the advantage over BSLs and specific line-weighting regimes as a mandatory mitigation measure, as it can be assessed remotely and in near real-time by inferring fishing activity from satellite detected automatic identification system (AIS) data on vessel movements (de Souza et al. 2016). While one reason night-setting may be successful is because albatrosses rarely forage nocturnally, our results only apply to dive behaviour during the breeding season when targeting natural prey. As such, they do not necessarily indicate a physiological maximum and it is possible that birds feeding behind vessels might dive deeper. Further work could usefully involve tracking diurnal activity patterns of albatrosses in contact with fisheries, as it cannot be assumed that the patterns seen here are representative of all populations or times of year.

In some regions, the smaller, deeper-diving Procellaria petrels and Ardenna shearwaters bring baited hooks to the surface, where they become accessible to albatrosses, putting the latter at risk. Jiménez et al (2012) observed that $41 \%$ of albatrosses killed on longlines were hooked on gear with which a medium-sized diving seabird had first made contact. Similar dynamics were reported in Melvin et al. (2014), where over half of the primary attacks (bait brought to the surface by a diving Procellaria petrel) led to a secondary attack on the bait, usually by an albatross. Despite their poor diving abilities, Thalassarche albatrosses are often the most frequently-killed surface-foraging birds at feeding assemblages, indicating the critical importance of mitigation designed to keep hooks beyond the reach of deeper-diving birds (Petersen et al. 2009; Melvin et al. 2013, 2014). In feeding assemblages where white-chinned petrels are the dominant species, a combination of two bird-scaring lines, weighted branch lines and night setting has the potential to reduce seabird bycatch to near zero (Melvin et al. 2014). Further research into areas of spatial overlap between deeper divers, threatened albatross species, and commercial longline fisheries would better identify potential bycatch hotspots where monitoring and mitigation efforts could be focused. In addition, the use of additional tracking devices such as high-resolution TDRs mounted on the head, accelerometers to reveal very shallow dives (Cianchetti-Benedetti et al. 2017), or stomach temperature probes, which provide information on the timing of ingestion and size of prey (Catry et al. 2004), would provide insights into the prey capture rate and profitability of diving compared with feeding close to the surface.

Supplementary Information The online version contains supplementary material available at https://doi.org/10.1007/s00227-021-03841-y.

Acknowledgements We are grateful to field workers, particularly Claudia Mischler, Derren Fox and Stacey Adlard for help with device deployment and retrieval. Thanks also to the five reviewers who provided many useful comments which helped improve the manuscript. This study represents a contribution to the Ecosystems Component of the British Antarctic Survey Polar Science for Planet Earth Programme, funded by the Natural Environmental Research Council.

Author contributions RAP, AM, and LKB conceived the ideas and designed the methodology. RAP collected data. AK and YRC processed raw TDR data. LKB analysed data and made figures. LKB led the writing of the manuscript. All authors contributed to the manuscript text, reviewed and edited, and gave final approval for publication.

Funding Fieldwork for this study was funded by Natural Environmental Research Council (NERC) core funding to British Antarctic Survey. LKB was funded by the Gates Cambridge Trust

Availability of data and material The GPS data are available for download from the BirdLife International Seabird Tracking Database. (http:// seabirdtracking.org/mapper/contributor.php?contributor_id=361; dataset ids: 1382,1383$)$. The immersion and dive datasets are available from the authors on reasonable request.

Code availability R Code used for analysis is available at https://githu b.com/lkbentley/diving.

\section{Compliance with ethical standards}

Conflicts of interest The authors declare that they have no conflicts of interest.

Ethics approval The tracking was approved by the British Antarctic Survey Ethics Committee and carried out with the permission of the Government of South Georgia and the South Sandwich Islands.

Open Access This article is licensed under a Creative Commons Attribution 4.0 International License, which permits use, sharing, adaptation, distribution and reproduction in any medium or format, as long as you give appropriate credit to the original author(s) and the source, provide a link to the Creative Commons licence, and indicate if changes were made. The images or other third party material in this article are included in the article's Creative Commons licence, unless indicated otherwise in a credit line to the material. If material is not included in the article's Creative Commons licence and your intended use is not permitted by statutory regulation or exceeds the permitted use, you will need to obtain permission directly from the copyright holder. To view a copy of this licence, visit http://creativecommons.org/licenses/by/4.0/. 


\section{References}

Anderson O, Small C, Croxall J, Dunn E, Sullivan B, Yates O, Black A (2011) Global seabird bycatch in longline fisheries. Endanger Species Res 14:91-106. https://doi.org/10.3354/esr00347

Bennison A, Bearhop S, Bodey TW, Votier SC, Grecian WJ, Wakefield ED, Hamer KC, Jessopp M (2018) Search and foraging behaviors from movement data: a comparison of methods. Ecol Evol 8:13-24. https://doi.org/10.1002/ece3.3593

Bull LS (2007) Reducing seabird bycatch in longline, trawl and gillnet fisheries. Fish Fish 8:31-56. https://doi.org/10.111 1/j.1467-2979.2007.00234.x

Burger AE, Wilson RP (1988) Capillary-tube depth gauges for diving animals: an assessment of their accuracy and applicability. J Field Ornithol 59:345-354

Calenge C (2006) The package adehabitat for the R software: a tool for the analysis of space and habitat use by animals. Ecol Model 197:516-519. https://doi.org/10.1016/j.ecolmodel.2006.03.017

Catry P, Phillips R, Phalan B, Silk J, Croxall J (2004) Foraging strategies of grey-headed albatrosses Thalassarche chrysostoma: integration of movements, activity and feeding events. Mar Ecol Prog Ser 280:261-273. https://doi.org/10.3354/meps280261

Cianchetti-Benedetti M, Catoni C, Kato A, Massa B, Quillfeldt P (2017) A new algorithm for the identification of dives reveals the foraging ecology of a shallow-diving seabird using accelerometer data. Mar Biol 164:77. https://doi.org/10.1007/s0022 7-017-3106-0

Clay TA, Small C, Tuck GN, Pardo D, Carneiro APB, Wood AG, Croxall JP, Crossin GT, Phillips RA (2019) A comprehensive large-scale assessment of fisheries bycatch risk to threatened seabird populations. J Appl Ecol 56:1882-1893. https://doi. org/10.1111/1365-2664.13407

Crawford R, Ellenberg U, Frere E, Hagen C, Baird K, Brewin P, Crofts S, Glass J, Mattern T, Pompert J, Ross K, Kemper J, Ludynia K, Sherley R, Steinfurth A, Suazo C, Yorio P, Tamini L, Mangel J, Bugoni L, Jiménez Uzcátegui G, Simeone A, LunaJorquera G, Gandini P, Woehler E, Pütz K, Dann P, Chiaradia A, Small C (2017) Tangled and drowned: a global review of penguin bycatch in fisheries. Endanger Species Res 34:373-396. https://doi.org/10.3354/esr00869

Croxall J, Prince P (1980) Food, feeding ecology and ecological segregation of seabirds at South Georgia. Biol J Linn Soc 14:103-131

de Souza EN, Boerder K, Matwin S, Worm B (2016) Improving fishing pattern detection from satellite ais using data mining and machine learning. PLoS ONE 11:e0158248. https://doi.org/10.1371/journ al.pone. 0158248

Goad D, Debski I, Potts J (2019) Hookpod-mini: a smaller potential solution to mitigate seabird bycatch in pelagic longline fisheries. Endanger Species Res 39:1-8. https://doi.org/10.3354/esr00953

Granadeiro JP, Campioni L, Catry P (2018) Albatrosses bathe before departing on a foraging trip: implications for risk assessments and marine spatial planning. Bird Conserv Int 28:208-215. https://doi. org/10.1017/S0959270916000459

Grémillet D, Péron C, Pons J-B, Ouni R, Authier M, Thévenet M, Fort J (2014) Irreplaceable area extends marine conservation hotspot off Tunisia: insights from GPS-tracking Scopoli's shearwaters from the largest seabird colony in the Mediterranean. Mar Biol 161:2669-2680

Harper P (1987) Feeding behaviour and other notes on 20 species of procellariiformes at sea. Notornis 34:169-192

Hedd A, Gales R, Brothers N, Robertson G (1997) Diving behaviour of the Shy Albatross Diomedea cauta in Tasmania: initial findings and dive recorder assessment. Ibis 139:452-460. https://doi. org/10.1111/j.1474-919X.1997.tb04658.x
Huin N, Prince PA (1997) Diving behaviour of the grey-headed albatross. Antarct Sci 9:243-249. https://doi.org/10.1017/S095410209 7000321

Jiménez S, Domingo A, Abreu M, Brazeiro A (2012) Bycatch susceptibility in pelagic longline fisheries: are albatrosses affected by the diving behaviour of medium-sized petrels? Aquat Conserv Mar Freshw Ecosyst 22:436-445. https://doi.org/10.1002/aqc.2242

Jiménez S, Phillips RA, Brazeiro A, Defeo O, Domingo A (2014) Bycatch of great albatrosses in pelagic longline fisheries in the southwest Atlantic: contributing factors and implications for management. Biol Conserv 171:9-20. https://doi.org/10.1016/j.bioco n.2013.12.035

Jiménez S, Domingo A, Forselledo R, Sullivan BJ, Yates O (2018) Mitigating bycatch of threatened seabirds: the effectiveness of branch line weighting in pelagic longline fisheries. Anim Conserv 22:376-385. https://doi.org/10.1111/acv.12472

Jiménez S, Domingo A, Winker H, Parker D, Gianuca D, Neves T, Coelho R, Kerwath S (2020) Towards mitigation of seabird bycatch: large-scale effectiveness of night setting and Tori lines across multiple pelagic longline fleets. Biol Conserv 247:108642. https ://doi.org/10.1016/j.biocon.2020.108642

Kazama K, Harada T, Deguchi T, Suzuki H, Watanuki Y (2019) Foraging behavior of Black-Footed Albatross Phoebastria nigripes rearing chicks on the Ogasawara Islands. Ornithol Sci 18:27-37. https://doi.org/10.2326/osj.18.27

Mackley EK, Phillips RA, Silk JRD, Wakefield ED, Afanasyev V, Furness RW (2011) At-sea activity patterns of breeding and nonbreeding white-chinned petrels Procellaria aequinoctialis from South Georgia. Mar Biol 158:429-438. https://doi.org/10.1007/ s00227-010-1570-x

Martin GR (1998) Eye structure and amphibious foraging in albatrosses. Proc R Soc Lond B Biol Sci 265:665-671. https://doi. org/10.1098/rspb.1998.0345

Matsumoto K, Oka N, Ochi D, Muto F, Satoh TP, Watanuki Y (2012) Foraging behavior and diet of streaked shearwaters Calonectris leucomelas rearing chicks on Mikura Island. Ornithol Sci 11:919. https://doi.org/10.2326/osj.11.9

Melvin EF, Guy TJ, Read LB (2013) Reducing seabird bycatch in the South African joint venture tuna fishery using bird-scaring lines, branch line weighting and nighttime setting of hooks. Fish Res 147:72-82. https://doi.org/10.1016/j.fishres.2013.04.015

Melvin EF, Guy TJ, Read LB (2014) Best practice seabird bycatch mitigation for pelagic longline fisheries targeting tuna and related species. Fish Res 149:5-18. https://doi.org/10.1016/j.fishr es.2013.07.012

Navarro J, Votier SC, Phillips RA (2014) Diving capabilities of diving petrels. Polar Biol 37:897-901. https://doi.org/10.1007/s0030 0-014-1483-0

Paiva V, Xavier J, Geraldes P, Ramirez I, Garthe S, Ramos J (2010) Foraging ecology of Cory's shearwaters in different oceanic environments of the North Atlantic. Mar Ecol Prog Ser 410:257-268. https://doi.org/10.3354/meps08617

Pardo D, Forcada J, Wood AG, Tuck GN, Ireland L, Pradel R, Croxall JP, Phillips RA (2017) Additive effects of climate and fisheries drive ongoing declines in multiple albatross species. Proc Natl Acad Sci 114:E10829-E10837. https://doi.org/10.1073/ pnas. 1618819114

Péron C, Grémillet D, Prudor A, Pettex E, Saraux C, Soriano-Redondo A, Authier M, Fort J (2013) Importance of coastal marine protected areas for the conservation of pelagic seabirds: the case of vulnerable yelkouan shearwaters in the Mediterranean Sea. Biol Conserv 168:210-221. https://doi.org/10.1016/j.bioco n.2013.09.006

Petersen SL, Honig MB, Ryan PG, Underhill LG, Goren $M$ (2009) Seabird bycatch in the demersal longline 
fishery off southern Africa. Afr J Mar Sci 31:205-214. https:// doi.org/10.2989/AJMS.2009.31.2.8.880

Phalan B, Phillips R, Silk J, Afanasyev V, Fukuda A, Fox J, Catry P, Higuchi H, Croxall J (2007) Foraging behaviour of four albatross species by night and day. Mar Ecol Prog Ser 340:271-286. https ://doi.org/10.3354/meps340271

Phillips RA, Xavier JC, Croxall JP (2003) Effects of satellite transmitters on albatrosses and petrels. Auk 120:1082-1090. https://doi. org/10.1093/auk/120.4.1082

Phillips R, Silk J, Croxall J (2005) Foraging and provisioning strategies of the light-mantled sooty albatross at South Georgia: competition and co-existence with sympatric pelagic predators. Mar Ecol Prog Ser 285:259-270. https://doi.org/10.3354/meps285259

Phillips RA, Croxall JP, Silk JRD, Briggs DR (2007) Foraging ecology of albatrosses and petrels from South Georgia: two decades of insights from tracking technologies. Aquat Conserv Mar Freshw Ecosyst 17:S6-S21. https://doi.org/10.1002/aqc.906

Phillips RA, Gales R, Baker GB, Double MC, Favero M, Quintana F, Tasker ML, Weimerskirch H, Uhart M, Wolfaardt A (2016) The conservation status and priorities for albatrosses and large petrels. Biol Conserv 201:169-183. https://doi.org/10.1016/j.bioco n.2016.06.017

Prince PA, Morgan R (1987) Diet and feeding ecology of Procellariiformes. Seabirds: feeding ecology and role in marine ecosystems. Cambridge University Press, Cambridge, pp 135-172

Prince PA, Huin N, Weimerskirch H (1994) Diving depths of albatrosses. Antarct Sci 6:353-354. https://doi.org/10.1017/S0954 102094000532

R Core Team (2019) R: a language and environment for statistical computing. R Foundation for Statistical Computing, Vienna, Austria

Robertson G, Ashworth P, Ashworth P, Carlyle I, Jiménez S, Forselledo R, Domingo A, Candy SG (2018) Setting baited hooks by stealth (underwater) can prevent the incidental mortality of albatrosses and petrels in pelagic longline fisheries. Biol Conserv 225:134 143. https://doi.org/10.1016/j.biocon.2018.06.026

Rollinson DP, Dilley BJ, Ryan PG (2014) Diving behaviour of white-chinned petrels and its relevance for mitigating longline bycatch. Polar Biol 37:1301-1308. https://doi.org/10.1007/s0030 0-014-1521-y

Rollinson DP, Dilley BJ, Davies D, Ryan PG (2016) Diving behaviour of Grey Petrels and its relevance for mitigating long-line by-catch. Emu Austral Ornithol 116:340-349. https://doi.org/10.1071/ MU15032

Sakamoto KQ, Takahashi A, Iwata T, Trathan PN (2009) From the eye of the albatrosses: a bird-borne camera shows an association between albatrosses and a killer whale in the southern ocean. PLoS ONE 4:e7322. https://doi.org/10.1371/journal.pone.00073 22
Scales KL, Miller PI, Ingram SN, Hazen EL, Bograd SJ, Phillips RA (2016) Identifying predictable foraging habitats for a wideranging marine predator using ensemble ecological niche models. Divers Distrib 22:212-224. https://doi.org/10.1111/ddi.12389

Shaffer S, Weimerskirch H, Scott D, Pinaud D, Thompson D, Sagar P, Moller H, Taylor G, Foley D, Tremblay Y, Costa D (2009) Spatiotemporal habitat use by breeding sooty shearwaters Puffinus griseus. Mar Ecol Prog Ser 391:209-220. https://doi.org/10.3354/ meps07932

Shoji A, Dean B, Kirk H, Freeman R, Perrins CM, Guilford T (2016) The diving behaviour of the Manx Shearwater Puffinus puffinus. Ibis 158:598-606. https://doi.org/10.1111/ibi.12381

Sullivan B, Kibel B, Kibel P, Yates O, Potts J, Ingham B, Domingo A, Gianuca D, Jiménez S, Lebepe B (2018) At-sea trialling of the Hookpod: a 'one-stop'mitigation solution for seabird bycatch in pelagic longline fisheries. Anim Conserv 21:159-167

Sumner MD, Wotherspoon SJ, Hindell MA (2009) Bayesian estimation of animal movement from archival and satellite tags. PLoS ONE 4:e7324. https://doi.org/10.1371/journal.pone.0007324

Tancell C, Sutherland WJ, Phillips RA (2016) Marine spatial planning for the conservation of albatrosses and large petrels breeding at South Georgia. Biol Conserv 198:165-176. https://doi. org/10.1016/j.biocon.2016.03.020

Thomson RB, Alderman RL, Tuck GN, Hobday AJ (2015) Effects of climate change and fisheries bycatch on Shy Albatross (Thalassarche cauta) in Southern Australia. PLoS ONE. https://doi. org/10.1371/journal.pone.0127006

Warham J (1996) The behaviour, population biology and physiology of the petrels. Academic Press, London, UK

Weimerskirch H, Guionnet T (2002) Comparative activity pattern during foraging of four albatross species. Ibis 144:40-50. https://doi. org/10.1046/j.0019-1019.2001.00021.x

Weimerskirch H, Lys P (2000) Seasonal changes in the provisioning behaviour and mass of male and female wandering albatrosses in relation to the growth of their chick. Polar Biol 23:733-744. https ://doi.org/10.1007/s003000000144

Weimerskirch H, Pinaud D, Pawlowski F, Bost C-A (2007) Does prey capture induce area-restricted search? A fine-scale study using GPS in a marine predator, the wandering albatross. Am Nat 170:734-743

Žydelis R, Small C, French G (2013) The incidental catch of seabirds in gillnet fisheries: a global review. Biol Conserv 162:76-88

Publisher's Note Springer Nature remains neutral with regard to jurisdictional claims in published maps and institutional affiliations. 